\title{
Risk factors for myopia in Inner Mongolia medical students in China
}

\author{
Yanyan $\mathrm{Wu}^{1}$, He Yi ${ }^{1}$, Wenzhong Liu ${ }^{1}$, Haiying Jia ${ }^{1}$, Yuki Eshita ${ }^{2}$, Shubi Wang ${ }^{3}$, Peng Qin ${ }^{4}$, Juan Sun ${ }^{{ }^{*}}$ \\ ${ }^{1}$ Inner Mongolia Medical University, Hohhot, China \\ ${ }^{2}$ Oita University, Faculty of Medicine, Oita, Japan \\ ${ }^{3}$ Tongliao Hospital, Tongliao, China \\ ${ }^{4}$ Inner Mongolia People's Hospital, Hohhot, China \\ Email: *cnsunjuan@yahoo.com.cn
}

Received 15 August 2012; revised 22 September 2012; accepted 15 December 2012

\begin{abstract}
Objective: The aim of the study was to investigate myopia and related factors in Inner Mongolia Medical Students, China. Methods: The survey employed a self-administered questionnaire. All medical students from the Inner Mongolia Medical University campus and those living and learning on campus were eligible. The questionnaire consisted of three sections: students' basic information, attitude on myopia behavior, and myopia status of students. 6047 medical students completed the questionnaire. Results: A total of 6040 (90.5\%) students aged 16 to 28 years (mean $21 \pm 1.5$ years) completed the questionnaire, of which 1772 (29.3\%) were male and $4268(70.6 \%)$ were female. The Mongolia of medical students had the lowest rate (64.3\%) of myopia. The prevalence of myopia in Han nationality was highest $(\mathbf{7 2 . 8 \% )}$. Myopia occurred more frequently among students living in the city than in the rural. $76.4 \%$ urban and $66.6 \%$ rural students had myopia $(p<0.001)$. For myopia students it was established that $85.5 \%$ had begun to wear spectacles in middle school. Conclusion: A high myopia prevalence was demonstrated among medical students in the Inner Mongolia area of China. Our study's findings could help health care professionals develop targeted myopia control policies for the population of students in Inner Mongolia of China and ensure the policies are more rational, useful, and effective.
\end{abstract}

Keywords: Medical Students; Myopia; Prevalence; Ethnicity; Area

\section{INTRODUCTION}

"Myopia is a global public health problem leading to

${ }^{*}$ Corresponding author. visual impairment and blinding complications" [1]. "The aetiology of myopia is multifactorial and both genes and environment play important roles. Twin studies indicate a strong genetic influence and aweak environmental impact" [2]. "However, results from experimental studies, including in primates, support the evidence of environmental factors from human epidemiology. These studies show that changes in visual experience by fitting of diffusers or both positive and negative lenses over the eyes can generate signals that promote eye growth, leading to myopia, as well as signals that slow eye growth." [3] Vitale, et al. [4] "compared data between the periods 1971-1972 and 1999-2004 in the USA. The study, "using similar methodology to collect data from both periods, finds a significant increase from 25 to $41.6 \%(\mathrm{p}<0.001)$ in rates of myopia in both men and women cohorts between the ages of 12 and 54" [4]. The prevalence of myopia is also increasing in Europe as well [5]. "In developed countries in east and southeast Asia, such as Singapore, China, Taiwan, Hong Kong, Japan, and Korea, the prevalence of myopia has rapidly increased in the past 50 - 60 years" [6,7]. The economic costs of myopia are also high. "In the United States, the National Health and Nutrition Examination Survey (NHANES) reported the annual direct cost of correcting distance vision impairment due to refractive errors to be between US\$3.9 and US\$7.2 billion" [8]. "In Singapore, the mean annual direct cost of myopia for each Singaporean school children aged 7 - 9 years was estimated to be US\$148" [9]. "The medical burden of high myopia includes pathologic complications such as myopic macular degeneration, choroidal neovascularisation, cataract and glaucoma" [1]. "Uncorrected refractive error could also impair vision-related quality of life and increase difficulty in performing vision-relatedtasks" [10].

Therefore, these factors "call for adequate diagnosis and correction of myopic refractive errors, effective treatment of myopic pathologies, and, above all, prevention 
of myopia" [11]. In the past few decades, "numerous epidemiology studies have provided information on the pattern of prevalence and risk factors for myopia" [1214]. "Population-based studies with sufficient sample sizes, high response rates and few biases provide the strongest evidence for examining the aetiology of myopia" [7]. Until now, in Inner Mongolia, no study has been conducted on the prevalence of myopia among Han, Mongolia and other nationality. Consequently, we tend to explore the epidemiology of myopia in our university undergraduates and to evaluate the association between myopia, ethnicity, area, and attitude of myopia behavior among medical students of Inner Mongolia Medical University.

\section{MATERIALS AND METHODS}

The data analysed in our study came from a questionnaire survey of physical and mental health for the university students. The purpose of previous study was to determine the prevalence of and factors associated with daily smoking [15], myopia, body weight levels and the physical health status [16], etc. among medical students in Inner Mongolia of China. Jiang Bian et al. [15] reported that the test-retest reliability was $96.4 \%$, the range of the Kappa index $6.03-8.03$, and the average value of the Kappa index 7.13.

\subsection{Research Targets}

"A cross-sectional survey was conducted among medical students at the Inner Mongolia Medical College of China who resided on campus at the time of the survey. The survey focused on medical students and employed a self-administered questionnaire. At the time of the survey, a total of 6677 students were present at the Inner Mongolia Medical College campus" [15].

\subsection{Questionnaire and Measures}

"Subjects myopia were those who gave details about the age at which they started to wear spectacles or contact lenses. If they used spectacles or contact lens for looking at far objects, the parent was classified as myopic" [13]. Participants excluded from analyses included those reporting a history of cataract and/or glaucoma. The first concentrated on visual problems with distance or near vision, use of spectacles or contact lenses, attitude regarding myopia behavior and a self-reported medical history of cataract and/or glaucoma. The second included epidemiological variables such as age, gender and family ocular history. These data will be presented elsewhere. The third section was only answered by myopia students, and contained 4 questions about the attitude regarding myopia behavior.
In terms of the Mongolian ethnic minority, we divided ethnicity into 3 categories: Han, Mongolian, and other. Participants' ethnicity information came from their basic information contained in the school database. The dates were same with Jiang Bian et al. [15] reported. Students coming from an urban area or suburb (area surrounding an urban area and under the jurisdiction of an urban government) were defined as city students, while those coming from a village or pastoral area were defined as rural students.

\subsection{Statistical Analysis}

Age of students was expressed as the mean age and standard deviation (SD) [15]. We investigated demographic characteristics between myopia and the following factors: gender, ethnicity, area, picky eater, have a rest after reading one hour, use computers, do eye exercises and number of myopic parents (all of which were in the survey). All variables were placed in a model of binary logistic regression analysis to ascertain factors associated with myopia. This technique is used for analyses with dependent variables with two levels (myopic and non-myopic in this case). Independent variables included in the model were gender (male/female), ethnicity (han nationality, mongolia, other nationality), area (city/rural), picky eater (yes/no), have a rest after reading one hour (yes/no), use computers (yes/no), do eye exercises (yes/ no), number of myopic parents (zero, one, two), time of go to bed (before 22:00, 22:00-00:00, after 00:00, nothing regular) and the attitude of the participants to the myopia behavior.

Quantitative data were entered using EpiDate (EpiData Association, Denmark; v3.1). For all analyses, we used SPSS for Windows v13.0. A two-tailed $\mathrm{p}<0.05$ was considered statistically significant.

\subsection{Ethical Approval}

The project was approved by the Ethical Committee of Inner Mongolia. Participants' written informed consent was obtained.

\section{RESULTS}

A total of $6044(90.5 \%)$ students aged 16 to 28 years (mean $21 \pm 1.5$ years) completed the questionnaire, of which 1772 (29.3\%) were male and 4268 (70.6\%) were female. Table 1 provides the baseline characteristics of the study participants and the prevalence of myopia in relation to each survey item. The myopia prevalence among Inner Mongolia medical students was $70.5 \%$ and the prevalence of myopia among females was higher than among male medical students $(72.8 \%$ vs. $65.0 \%)$. The prevalence of myopia was $72.8 \%$ among the Han nationality, $64.3 \%$ Mongolia nationality and $67.0 \%$ 
Table 1. Selected characteristics in myopic students.

\begin{tabular}{|c|c|c|c|}
\hline Variable & N (\%) & $\begin{array}{l}\text { Myopic } \\
\text { n (\%) }\end{array}$ & $95 \%$ CI \\
\hline \multicolumn{4}{|l|}{ Gender $(n=6040)$} \\
\hline Male & $1772(29.3)$ & 65.0 & $62.8-67.2$ \\
\hline Female & 4268 (70.6) & 72.8 & $71.5-74.1$ \\
\hline \multicolumn{4}{|l|}{ Ethnicity $(n=6040)$} \\
\hline Han nationality & $4314(71.4)$ & 72.8 & $71.5-74.1$ \\
\hline Mongolia & $1405(23.3)$ & 64.3 & $61.8-66.8$ \\
\hline Other nationality & $321(5.3)$ & 67.0 & $61.9-72.1$ \\
\hline \multicolumn{4}{|l|}{ Area $(n=5924)$} \\
\hline City & $2483(41.3)$ & 76.4 & $74.7-78.1$ \\
\hline Rural & $3535(58.7)$ & 66.6 & $65.0-68.2$ \\
\hline \multicolumn{4}{|c|}{ Picky eater $(n=5949)$} \\
\hline No & $3769(63.4)$ & 70.8 & $69.3-72.3$ \\
\hline Yes & $2180(36.6)$ & 71.4 & $69.5-73.3$ \\
\hline \multicolumn{4}{|l|}{$\begin{array}{l}\text { Have a rest after } \\
\text { reading one hour }\end{array}$} \\
\hline No & 4809 (80.9) & 74.2 & $73.0-75.4$ \\
\hline Yes & $1105(19.1)$ & 57.4 & $54.5-60.3$ \\
\hline \multicolumn{4}{|l|}{ Use computers } \\
\hline No & $52(0.9)$ & 46.2 & $32.6-59.8$ \\
\hline Yes & $5988(99.1)$ & 70.8 & $69.6-72.0$ \\
\hline \multicolumn{4}{|l|}{$\begin{array}{l}\text { Do eye exercises } \\
\quad(n=6025)\end{array}$} \\
\hline No & $3498(58.1)$ & 73.9 & $72.4-75.3$ \\
\hline Yes & 2527 (41.9) & 66.2 & $64.4-68.0$ \\
\hline \multicolumn{4}{|l|}{$\begin{array}{l}\text { Number of myopic } \\
\text { parents }(n=6040)\end{array}$} \\
\hline Zero & $5163(85.5)$ & 68.1 & $66.8-68.4$ \\
\hline One & $754(12.5)$ & 83.8 & $81.2-86.4$ \\
\hline Two & $123(2.03)$ & 91.1 & $87.1-96.7$ \\
\hline \multicolumn{4}{|l|}{$\begin{array}{l}\text { Time of go to bed } \\
\quad(n=6026)\end{array}$} \\
\hline Before 22:00 & $112(1.9)$ & 61.6 & $52.6-70.6$ \\
\hline 22:00-00:00 & $4406(73.1)$ & 70.4 & $69.1-71.7$ \\
\hline After 00:00 & $1114(18.5)$ & 71.9 & $69.3-74.5$ \\
\hline Nothing regular & $394(6.5)$ & 72.3 & $67.9-76.7$ \\
\hline
\end{tabular}

among the other nationality. The Han nationality of students with highest prevalence of myopia in inter Mongolia medical university. $76.4 \%$ urban and $66.6 \%$ rural students had myopia. It was observed that myopia oc- curred more frequently among students living in the city than in the rural. The myopia prevalence in students who had one or two myopic parents was higher than in those without myopic parents. The myopia prevalence was 1.29 times higher for those students who did not have a rest after reading one hour compared to those who have a rest after reading one hour.

We included all factors in binary logistic regression models (Table 2). Univariate logistic regression analysis determined that age was significantly associated with myopia: 1.0 (ref) in male, score of adjustment to the female $(\mathrm{OR}=1.42, \mathrm{p}<0.001) ; 1.0$ (ref) in Han nationality, score of adjustment to the Mongolia ethnicity $(\mathrm{OR}=0.68$, $\mathrm{p}<0.001$ ); 1.0 (ref) in city, score of adjustment to the rural area $(\mathrm{OR}=0.74, \mathrm{p}<0.001)$. Number of myopic parents: 1.0 (ref) in zero parent, one parent $\mathrm{OR}=2.02$, two parents $\mathrm{OR}=3.62, \mathrm{p}<0.001$. Significant difference in students' myopia prevalence was found for students who have a rest after reading one hour $(p<0.001)$. The attitudes of students toward myopia behavior showed statistical significance: Do more physical exercises are good for your eyes $(\mathrm{p}<0.05$; Table 2$)$.

In Table 3, for myopia students (4261) it was established that $85.5 \%$ had begun to wear spectacles in middle school. Only $28.6 \%$ myopia students go to the ophthalmic hospital to fit for spectacles. More than $90 \%$ of myopia students often rubbed their eyes by hands. Among all the questioned myopia students, 136 of the students have a habit of wearing contact lenses for a long time.

\section{DISCUSSION}

Our study shows that the myopia prevalence among medical students is $70.5 \%$, with a higher prevalence among female students $(72.8 \%)$ compared to male students $(65.0 \%)$. These finding are similar to results of another Chinese study in Weifang Medical University [17]. This is considerably higher compared to the recently reported prevalence of myopia among general population in Western countries; $33.1 \%$ in the United States [18], 35.0\% in Norway [5], 26.6\% in Western Europe and $16.4 \%$ in Australia [19]. Compared with medical students in other countries, the prevalence of myopia in our study is also considerably higher: myopia is the most common vision condition affecting approximately $50 \%$ of European medical students [12] 50.0\% (45.0\% and $53.9 \%$ for males and females, respectively), in Denmark [12] 50.3\% in Norway [20] and 42\% in Polish [21]. Our data additionally show that the prevalence of myopia is more common in females, similar to another study of university students [22,23].

Our study shows that living in an urban or a rural environment may have an influence on the occurrence of myopia among students. "Inner Mongolia has vast terri- 
Table 2. Results of logistic regression analysis of myopia among medical students.

\begin{tabular}{|c|c|c|c|c|c|c|}
\hline & B & S.E. & Wald & $\mathbf{p}$ & OR & OR $(95 \% \mathrm{CI})$ \\
\hline Gender $(n=6040)$ & & & & $0.000^{* *}$ & & \\
\hline Male & & & & & 1 & \\
\hline Female & 0.352 & 0.067 & 27.598 & & 1.421 & $1.247-1.620$ \\
\hline Ethnicity $(n=6040)$ & & & 34.478 & $0.000^{* *}$ & & \\
\hline Han nationality & & & & & 1 & \\
\hline Mongolia & -0.389 & 0.071 & 29.814 & & 0.678 & $0.590-0.779$ \\
\hline Other nationality & -0.390 & 0.134 & 8.503 & & 0.677 & $0.521-0.880$ \\
\hline Area $(n=5924)$ & & & & $0.000^{* *}$ & & \\
\hline City & & & & & 1 & \\
\hline Rural & -0.307 & 0.066 & 21.906 & & 0.736 & $0.647-0.837$ \\
\hline Picky eater $(n=5949)$ & & & & 0.799 & & \\
\hline No & & & & & 1 & \\
\hline Yes & -0.016 & 0.064 & 0.065 & & 0.984 & $0.868-1.115$ \\
\hline Have a rest after reading one hour & & & & $0.000^{* *}$ & & \\
\hline No & & & & & 1 & \\
\hline Yes & -0.591 & 0.076 & 60.990 & & 0.554 & $0.477-0.642$ \\
\hline Use computers & & & & 0.091 & & \\
\hline No & & & & & 1 & \\
\hline Yes & 0.583 & 0.345 & 2.849 & & 1.791 & $0.910-3.525$ \\
\hline Do eye exercises (n=6025) & & & & $0.000^{* *}$ & & \\
\hline No & & & & & 1 & \\
\hline Yes & -0.289 & 0.061 & 22.604 & & 0.749 & $0.665-0.844$ \\
\hline Number of myopic parents $(n=6040)$ & & & & $0.000^{* *}$ & & \\
\hline Zero & & & 53.603 & & 1 & \\
\hline One & 0.704 & 0.111 & 40.073 & & 2.023 & $1.626-2.516$ \\
\hline Two & 1.287 & 0.324 & 15.768 & & 3.622 & $1.919-6.838$ \\
\hline Time of go to bed $(n=6026)$ & & & 1.534 & 0.674 & & \\
\hline Before 22:00 & & & & & 1 & \\
\hline 22:00-00:00 & -0.142 & 0.230 & 0.383 & & 0.867 & $0.553-1.362$ \\
\hline After 00:00 & -0.225 & 0.241 & 0.870 & & 0.799 & $0.498-1.280$ \\
\hline Nothing regular & -0.118 & 0.258 & 0.208 & & 0.889 & $0.536-1.474$ \\
\hline Often see green is good for your eyes & & & & 0.052 & & \\
\hline No & & & & & 1 & \\
\hline Yes & -0.173 & 0.089 & 3.778 & & 0.841 & $0.706-1.001$ \\
\hline Use of eye drops is good for your eyes & & & & 0.449 & & \\
\hline No & & & & & 1 & \\
\hline Yes & -0.060 & 0.079 & 0.574 & & 0.942 & $0.806-1.100$ \\
\hline $\begin{array}{c}\text { Do more physical exercises is good for } \\
\text { your eyes }\end{array}$ & & & & $0.015^{*}$ & & \\
\hline No & & & & & 1 & \\
\hline Yes & -0.251 & 0.104 & 5.882 & & 0.778 & $0.635-0.935$ \\
\hline Reading while lying is bad for your eyes & & & & 0.581 & & \\
\hline No & & & & & 1 & \\
\hline Yes & 0.087 & 0.158 & 0.304 & & 1.091 & $0.800-1.478$ \\
\hline
\end{tabular}

${ }^{*} \mathrm{p}<0.05 ;{ }^{* *} \mathrm{p}<0.01$. 
Table 3. The myopia status of students in Inner Mongolia Medical University. $\mathrm{N}=4261$.

\begin{tabular}{ccc}
\hline Category & $\mathbf{n}$ & (n/N) (\%) \\
\hline When wear spectacles $\mathbf{n}=\mathbf{3 9 4 9}$ & 14 & 0.4 \\
Kindergarten & 307 & 7.8 \\
Primary school & 3375 & 85.5 \\
Middle school & 398 & 6.4 \\
University & & \\
Where be fitted for spectacles $\mathbf{n}=\mathbf{4 0 9 8}$ & 1172 & 28.6 \\
Ophthalmic hospital & 2706 & 66.0 \\
Eyeglasses Store & 220 & 5.4 \\
Both of them & & \\
Wear contact lens $\mathbf{n}=\mathbf{4 1 0 9}$ & 3978 & 96.8 \\
No & 131 & 3.2 \\
Yes & & \\
Yes & 320 & 7.5 \\
No & 3936 & 92.5 \\
\hline Often rubbed eyes by heads $\mathbf{n}=\mathbf{4 2 5 6}$ & &
\end{tabular}

tory and long nomadic history, which cause the imbalance development between rural area and city area, so there is a large difference in living environment between rural area and city area" [15]. "The importance of environmental risk factors is strongly supported by experimentation with animals, and by the rapid changes in the prevalence of myopia. Associations of myopia with years of schooling and school results have been consistently reported" [6]. "The rise in myopia prevalence in urban east Asia might therefore be plausibly associated with the increasing intensity of education. Moreover, east Asian countries with high myopia now dominate international rankings of educational performance, according to the Organ isation for Economic Co-operation and Development (OECD) Programme for International Student Assessment" [11].

"Myopia is thought to be multi-factorial with environmental and genetic factors as well as their interactions being involved" [23,24]. The present study supported such observation. We found that myopia prevalence among different ethnic groups was different. Mongolia is considered one of China's five minority areas. The Mongolia of medical students had the lowest rate $(64.3 \%)$ of myopia. The prevalence of myopia in Han nationality was highest $(72.8 \%)$. Several studies demonstrates the association of PAX6 variants with susceptibility to high myopia. "The PAX6 locus may contain polymorphisms playing a role in high myopia in southern Han Chinese"

\section{[24,25].}

Also our studies showed a higher proportion of myopic students among families with two myopic parents compared with one and no-myopic-parent families. This accord with previous research: "parental history of myopia has been postulated to be an important risk factor for the development of myopia" [26,27]. These results all support some genes influence in the etiology of myopia.

Several findings in current study can be used to inform the development of effective health promotion programs to prevent myopia among medical university students. First, as have a rest after reading one hour was recently shown to be another major factor, it is possible that increased rest after reading one hour may protect against myopia. Because of the "eyes are harmed by continuous reading" [2].

Second, our study also suggesting eye exercises and physical exercises are helpful. Eye exercises and physical exercises are protective factor for myopia. "We did not find any studies suggesting eye exercises are harmful" [28]. "An association between physical activity and myopia was observed, suggesting a protective effect of physical exercises on the development and progression of myopia in university students [29]." School managers should attempt made to "reduce accommodative fatigue by introducing pauses during reading and teaching and by eye exercises, etc. have been successful in reducing the number of students who develop myopia" [2].

Third, over $80 \%$ myopia students had begun to wear spectacles at middle school. "Added to this concern is myopia progression in teenage school students is very important" [30].

Fourth, over half of myopia students were not fitted for spectacles in ophthalmic hospital. "The extent of disability may be greater if myopia is not optimally corrected with appropriate spectacles or contact lenses" [30].

Fifth, more than $90 \%$ of myopia students often rubbed their eyes by hands. It is well known that if you don't pay attention to hygiene of eyes and often rubbing the eyes with dirty hands that causing eye irritation. In addition, there are 136 medical students still have a habit of wearing contact lenses for a long time. "Contact lens wear is known to lead to squamous metaplasia on the ocular surface" [31], "which is the primary cause of contact lens intolerance and has been identified in most ocular surface disorders, particularly in dry eye" [32]. Students must break those bad habits can be good for the eyes.

Based on the above research, school administrators should encourage them to actively participate in training and education to improve attitudes toward myopia, to increase protective factors, and reduce the risk factors for myopia behavior.

The present study had limitation. Myopia behavior 
was assessed on the basis of self-reported data only, without the use of biochemical measurements.

\section{CONCLUSION}

A high myopia prevalence was demonstrated among medical students in the Inner Mongolia area of China. Our study's findings could help health care professionals develop targeted myopia control policies for the population of students in Inner Mongolia of China and ensure the policies are more rational, useful, and effective.

\section{REFERENCES}

[1] Saw, S.-M., Gazzard, G., Shih-Yen, E.C. and Chua, W.-H. (2005) Myopia and associated pathological complications. Ophthalmic Physiological Optics, 25, 381-391. doi:10.1111/j.1475-1313.2005.00298.x

[2] Goldschmidt, E. (2003) The mystery of myopia. Acta Ophthalmologica Scandinavica, 81, 431-436. doi:10.1034/j.1600-0420.2003.00145.x

[3] Wallman, J. and Winawer, J. (2004) Homeostasis of eye growth and the question of myopia. Neuron, 43, 447-468. doi:10.1016/j.neuron.2004.08.008

[4] Vitale, S., Sperduto, R.D. and Ferris, F.L. (2009) Increased prevalence of myopia in the United States between 1971-1972 and 1999-2004. Archives of Ophthalmology, 127, 1632-1639.

doi:10.1001/archophthalmol.2009.303

[5] Midelfart, A., Kinge, B., Midelfart, S. and Lydersen, S. (2002) Prevalence of refractive errors in young and middle-aged adults in Norway. Acta Ophthalmologica Scandinavicai, 80, 501-505. doi:10.1034/j.1600-0420.2002.800508.x

[6] Morgan, I. and Rose, K. (2005) How genetic is school myopia. Progress in Retinal and Eye Research, 24, 1-38. doi:10.1016/j.preteyeres.2004.06.004

[7] Pan, C.W., Ramamurthy, D. and Saw, S.M. (2012) World-wide prevalence and risk factors for myopia. Ophthalmic Physiological Optics, 32, 3-16. doi:10.1111/j.1475-1313.2011.00884.x

[8] Vitale, S., Cotch, M.F., Sperduto, R. and Ellwein, L. (2006) Costs of refractive correction of distance vision impairment in the United States, 1999-2002. Ophthalmology, 113, 2163-2170.

doi:10.1016/j.ophtha.2006.06.033

[9] Lim, M.C.C., Gazzard, G., Sim, E.-L., Tong, L. and Saw, S.-M. (2009) Direct costs of myopia in Singapore. Eye, 23, 1086-1089. doi:10.1038/eye.2008.225

[10] Vu, H.T.V., Keeffe, J.E., McCarty, C.A. and Taylor, H.R. (2005) Impact of unilateral and bilateral vision loss on quality of life. British Journal of Ophthalmology, 89, 360-363. doi:10.1136/bjo.2004.047498

[11] Morgan, I.G., Ohno-Matsui, K. and Saw, S.-M. (2012) Myopia. Ophthalmology, 379, 1739-1748.

[12] Fledelius, H. (2000) Myopia profile in Copenhagen medical students 1996-1998. Refractive stability over a century is suggested. Acta Ophthalmologica Scandinavica, 78, 501-505.

doi:10.1034/j.1600-0420.2000.078005501.x

[13] Low, W., Dirani, M., Gazzard, G., Chan, Y.-H., Zhou, H.-J., Selvaraj, P., Eong, K.-G.A., Young, T.L., Mitchell, P., Wong, T.-Y. and Saw, S.-M. (2010) Family history, near work, outdoor activity, and myopia in Singapore Chinese preschool children. British Journal of Ophthalmology, 94, 1012-1016. doi:10.1136/bjo.2009.173187

[14] Mutti, D., Mitchell, G., Moeschberger, M., Jones, L. and Zadnik, K. (2002) Parental myopia, near work, school achievement, and children's refractive error. Investigative Ophthalmology Visual Science, 43, 3633-3640.

[15] Bian, J., Du, M., Liu, Z., Fan, Y., Eshita,Y. and Sun, J. (2012) Prevalence of and factors associated with daily smoking among Inner Mongolia medical students in China: A cross-sectional questionnaire survey. Substance Abuse Treatment, Prevention, and Policy, 7, 20. doi:10.1186/1747-597X-7-20

[16] Bian, J., Yi, H., Liu, Z.Y., Li, G.M., Ba, T., Zhang, Q. and Sun, J. (2012) Prevalence of and factors associated with various level of body weight among Inner Mongolia medical students in China. Open Journal of Preventive Medicine, 2, 123-130. doi:10.4236/ojpm.2012.22018

[17] Lv, L. and Zhang, Z. (2012) Pattern of myopia progression in Chinese medical students: A two-year followup study. Graefe's Archive for Clinical and Experimental Ophthalmology, 12, 2074-2079. http://www.ncbi.nlm.nih.gov/pubmed/22678717

[18] Vitale, S., Ellwein, L., Cotch, M.F., Ferris, F.L. and Sperduto, R. (2008) Prevalence of refractive error in the United States, 1999-2004. Archives of Ophthalmology, 126, 1111-1119. doi:10.1001/archopht.126.8.1111

[19] Kempen, J., Mitchell, P., Lee, K., Tielsch, J., Broman, A., Taylor, H., Ikram, M., Congdon, N., O'Colmain, B. and the Eye Diseases Prevalence Research Group (2004) The prevalence of refractive errors among adults in the United States, Western Europe, and Australia. Archives of Ophthalmology, 122, 495-505. doi:10.1001/archopht.122.4.495

[20] Midelfart, A., Aamo, B., Sjohaug, K.A. and Dysthe, B.E. (1992) Myopia among medical students in Norway. Acta Ophthalmologica Scandinavica, 70, 317-322. http://www.ncbi.nlm.nih.gov/pubmed/1636390

[21] Mozolewska-Piotrowska, K., Stepniewska, J. and Nawrocka, J. (2005) Frequency and incidence of myopia among medical students. Klinika Oczna, 107, 468-470. http://www.ncbi.nlm.nih.gov/pubmed/16416999

[22] Lam, C.S., Goldschmidt, E. and Edwards, M.H. (2004) Prevalence of myopia in local and international schools in Hong Kong. Optometry and Vision Science, 81, 317-322. doi:10.1097/01.opx.0000134905.98403.18

[23] Morgan, A., Young, R., Narankhand, B., Chen, S., Cottriall, C. and Hosking S. (2006) Prevalence rate of myopia in schoolchildren in rural Mongolia. Optometry and Vision Science, 83, 53-56. doi:10.1097/01.opx.0000195567.88641.af

[24] Shi, Y., Qu, J., Zhang, D.D., Zhao, P.Q., Zhang, Q.J., Tam, P.O.S., Sun, L.D., Zuo, X.T., Xiao, X.S., Hu, J.B., Li, T.F., 
et al. (2011) Genetic variants at 13q12.12 are associated with high myopia in the Han Chinese population. The American Journal of Human Genetics, 88, 805-813. http://www.ncbi.nlm.nih.gov/pubmed/21640322

[25] Han, W., Leung, K.H., Fung, W.Y., Mak, J.Y., Li, Y.M., Yap, M.K. and Yip, S.P. (2009) Association of PAX6 polymorphisms with high myopia in Han Chinese nuclear families. Investigative Ophthalmology Visual Science, 50, 1. http://www.ncbi.nlm.nih.gov/pubmed/19124844

[26] Jones-Jordan, L.A., Sinnott, L.T., Manny, R.E., Cotter, S.A., Kleinstein, R.N., Mutti, D.O., Twelker, J.D., Zadnik, $\mathrm{K}$. and the Collaborative Longitudinal Evaluation of Ethnicity and Refractive Error (CLEERE) Study Group (2010) Early childhood refractive error and parental history of myopia as predictors of myopia. Investigative Ophthalmology Visual Science, 51, 115-121. doi:10.1167/iovs.08-3210

[27] Jones, L.A., Sinnott, L.T., Mutti, D.O., Mitchell, G.L., Moeschberger, M.L. and Zadnik, K. (2007) Parental history of myopia, sports and outdoor activities, and future myopia. Investigative Ophthalmology Visual Science, 48, 8. doi:10.1167/iovs.06-1118

[28] Rawstron, J.A., Burley, C.D. and Elder, M.J. (2005) A systematic review of the applicability and efficacy of eye exercises. Journal of Pediatric Ophthalmology and Strabismus, 42, 82-88.

[29] Jacobsen, N., Jensen, H. and Goldschmidt, E. (2008) Does the level of physical activity in university students influence development and progression of myopia?-A 2-year prospective cohort study. Investigative Ophthalmology Visual Science, 49, 1322-1327. doi:10.1167/iovs.07-1144

[30] Saw, S.-M., Gazzard, G., Eong, K.-G.A. and Koh, D. (2003) Utility values and myopia in teenage school students. British Journal of Ophthalmology, 87, 341-345. doi:10.1136/bjo.87.3.341

[31] Cakmak, S.S., Unlu, M.K., Karaca, C., Nergiz, Y. and İpek, S. (2003) Effects of soft contact lenses on conjunctival surface. Eye and Contact Lens, 29, 230-233. doi:10.1097/01.icl.0000086492.28723.0C

[32] Rivas, L., Oroza, M.A., Perez-Esteban, A. and Murubedel-Castillo, J. (1992) Morphological changes in ocular surface in dry eyes and other disorders by impression cytology. Graefe's Archive for Clinical and Experimental Ophthalmology, 230, 329-334. doi:10.1007/BF00165940 